\title{
APRENDIZAGEM INFORMAL E SUAS IMPLICAÇÕES PRÁTICAS EM UM GRUPO DE TUTORES DE EDUCAÇÃO A DISTÂNCIA
}

\author{
Breno de Souza Ottani - UFSC - bre.ottani@gmail.com \\ Maristela Denise Coelho - UFSC - maricoelho_adm@ hotmail.com \\ Mileide Marlete Ferreira Leal Sabino - UFSC - mileide.sabino@ gmail.com \\ Marilda Todescat - UFSC - marildat@gmail.com
}

\begin{abstract}
RESUMO
O presente artigo objetivou analisar como ocorre a aprendizagem informal a partir da perspectiva de um grupo de tutores a distância do projeto Universidade Aberta do Brasil na Universidade Federal de Santa Catarina. A pesquisa é decorrente de um estudo de caso no qual a coleta de dados foi por meio de um questionário à equipe da Tutoria pertencente à quarta edição do curso de graduação em Administração do programa Universidade Aberta do Brasil. A análise das respostas demonstra que os meios de aprendizagem informal se apresentam como sendo mais efetivos na perspectiva dos tutores, ainda que exista preferência pela utilização de meios de comunicação formal, destacando-se o email institucional, o qual constitui uma base de informações essenciais para a consecução das atividades destes profissionais.
\end{abstract}

Palavras-chave: Aprendizagem informal. Tutoria. Educação a distância.

\begin{abstract}
This article aimed to analyze how informal learning occurs from the perspective of a group of distance tutors of the Open University of Brazil project at the Federal University of Santa Catarina. The research results from a case study in which the data collection was done through a questionnaire to the Tutorship team belonging to the fourth edition of the undergraduate program in Administration of the Open University of Brazil program. The analysis of the answers shows that the means of informal learning are presented as being more effective in the perspective of the tutors, although there is preference for the use of formal communication means, emphasizing the institutional email, which constitutes an information base Essential for the achievement of the activities of these professionals.
\end{abstract}

Keywords: Informal Learning. Tutoring. Distance education.

\section{INTRODUÇÃO}

O cenário atual onde as organizações estão inseridas requer muito mais do que apenas qualidade na prestação de seus serviços. Faz-se necessário que elas valorizem seu potencial enquanto geradoras de conhecimento e que identifiquem formas de proporcionar, através da aprendizagem, a renovação de seus processos e rotinas.

Bastos, Gondim e Loiola (2004) reforçam a importância do desenvolvimento da capacidade de aprender, pois é ela que permite o aperfeiçoamento de competências que habilitam a organização a identificar e reter novas informações com vistas à ampliação do conhecimento e melhoria dos processos e da tomada de decisão.

Os estudos em aprendizagem organizacional vêm sendo amplamente explorados nos últimos 30 anos (GHERARDI, 2006), e sua relevância é justificada em virtude da 
inserção das organizações em um contexto no qual novas demandas vêm surgindo por parte da sociedade e também por parte do trabalhador do conhecimento.

Estudos empíricos abordando o tema de aprendizagem organizacional tem se mostrado escassas, sobretudo aquelas que possuem como escopo a aprendizagem informal. Estima-se que $80 \%$ da aprendizagem dos indivíduos originam-se da aprendizagem informal, sendo que os $20 \%$ restantes são absorvidos por meio de aprendizagem formalmente estruturada (ANTONELLO, GODOY, 2011).

Por isso, a realização de pesquisas e trabalhos nesse campo vem cooperar com soluções para esse panorama, procurando atender tais gaps ao mesmo tempo em que contribuem para uma melhor qualificação profissional para atuar na educação a distância.

Em virtude da importância da tutoria no processo de ensino e aprendizagem do corpo discente, esta merece destaque também no que se refere aos aspectos relacionados à aprendizagem dos próprios tutores. Assim, o estudo das práticas de aprendizagem é fundamental visto que elas consistem de elementos que favorecem o processo educacional e pedagógico, bem como potencializem a competência de toda a equipe.

Desta forma, surge o interesse em pesquisar sobre a aprendizagem informal em uma equipe de tutores a distância. Ante o exposto, o objetivo do presente artigo é: analisar como ocorre a aprendizagem informal a partir da perspectiva de um grupo de tutores a distância do curso de graduação em Administração do projeto Universidade Aberta do Brasil na Universidade Federal de Santa Catarina.

\section{REFERENCIAL TEÓRICO} pesquisa.

Nesta seção são apresentadas as principais correntes teóricas sobre a presente

\subsection{APRENDIZAGEM ORGANIZACIONAL}

O termo aprendizagem organizacional vem sendo explorado por pesquisadores em diferentes níveis de análise e pontos de vistas, conforme destacam Antonello e Godoy (2011). Algumas perspectivas estudadas no campo de aprendizagem organizacional permeiam a psicologia, a sociologia, a antropologia, a ciência política, a história e a economia (ANTONELLO; GODOY, 2011).

Os estudos que se debruçam sobre o tema aprendizagem organizacional apoiamse basicamente em três tipos de abordagem: a cognitiva, a comportamental e a sociológica. A abordagem cognitiva pauta-se na premissa de que a aprendizagem é um processo que ocorre em nível individual, ou seja, na mente dos indivíduos, por meio de conexões mentais e ligações cerebrais. A abordagem comportamental, por sua vez, tem como foco de análise a ação do indivíduo após o estímulo para o processo de aprendizagem, ou seja, considera o comportamento frente a uma situação vivenciada. Já a abordagem sociocultural, ou sociológica, tem como fundamento o fato de que os significados, ações e o conhecimento adquirido são frutos das práticas sociais e coletivas. Estas práticas abrangem significados, artefatos, ações, trocas, experiências e o contexto sociocultural (FLACH; ANTONELLO, 2010; ANTONELLO; GODOY, 2011).

A aprendizagem organizacional sob o prisma sociológico se adapta melhor aos fins deste artigo, pois conforme elucida Gherardi (2001) essa perspectiva considera que a aprendizagem não ocorre na mente dos indivíduos, mas é algo produzido através das relações sociais entre grupos de pessoas na medida em que eles participam de uma sociedade. 
Partindo do pressuposto que a aprendizagem ocorre em um contexto específico e se origina nas trocas e interações entre os indivíduos, alguns estudos nacionais têm sido realizados visando compreender o fenômeno da aprendizagem organizacional e como ela ocorre (FLACH; ANTONELLO, 2010; ANTONELLO; GODOY, 2011; COELHO JÚNIOR; MOURÃO, 2011; BISPO; MELLO, 2012; BISPO, 2013).

\subsection{APRENDIZAGEM INFORMAL}

Para que seja possível analisar o fenômeno da aprendizagem informal nas organizações é preciso entender este tipo de aprendizagem se baseia, principalmente, na cultura, na socialização e nas práticas dos indivíduos.

Contudo, é importante conceituar a aprendizagem formal e indicar quais são as características que a distinguem da aprendizagem informal. Assim, a aprendizage m formal caracteriza-se por ser estruturada, apoiada institucionalmente, criada frequentemente com base no modelo de sala de aula, com a presença de um professor que ensina e avalia. (FLACH; ANTONELLO, 2011).

A aprendizagem informal não é frequentemente percebida pelos indivíduos em virtude de estar profundamente imbricada nas práticas cotidianas e pela ideia de que a aprendizagem é algo que está associada às formas convencionais de ensino e não baseada nas trocas e interações sociais. Ressalta-se que a aprendizagem informal pode ocorrer dentro de situações formalmente estruturadas, por exemplo, em cursos e treinamentos oferecidos pela organização. (WENGER, 2000; FLACH; ANTONELLO, 2010).

Esta forma de aprendizagem caracteriza-se por ser predominantemente experimental e não institucional, resultando de situações naturais do dia-a-dia, onde o indivíduo tem algum grau de consciência de que está aprendendo. (CONLON, 2004). O mesmo autor afirma ainda que a aprendizagem informal tem relevante impacto no desenvolvimento da expertise profissional.

Apesar de não poder ser controlada ou institucionalizada, a aprendizagem informal pode ser estimulada por meio de métodos como coaching, networking, suporte, colaboração do grupo, estímulos a atividades que não estejam necessariamente relacionadas às tarefas cotidianas, nos momentos de descontração e lazer, através de atividades artísticas de interesse dos participantes, entre outros (MARSICK; WATKINS, 1990).

No que pese o conceito de suporte à aprendizagem informal no trabalho, tratase de um construto que se constitui do apoio dado pela organização mediante ações específicas que corroboram a cultura de aprendizagem já mencionada (COELHO JUNIOR; MOURÃO, 2011). Este suporte pode ser expresso por meio do auxîlio em dúvidas, incentivo à produtividade e iniciativa, incentivo à comunicação entre colegas, auxilio na resolução de problemas, incentivo às novas formas de realizar as mesmas tarefas, tolerância ao erro, mentoria, análise dos impactos da aprendizagem, entre outras formas.

\subsection{TUTORIA E O PAPEL DO TUTOR}

Na perspectiva de Mill (2010), frente ao desafio de formação acadêmica na modalidade a distância no país, o tutor realiza um papel crucial dentro das instituições de ensino, e embora a complexidade de suas atividades em decorrência de inúmeros aspectos pedagógicos e de infraestrutura do $\mathrm{EaD}$ culminem, por vezes, na ausência ou parcialidade de seu reconhecimento, a discussão sobre o papel desse ator é crescente e confirma sua importância no âmbito organizacional. 
Ainda na ótica do autor, a tutoria da modalidade de ensino a distância é composta por uma estrutura polidocente, tanto pela pluralidade de áreas de formação quanto pelos papéis/funções desempenhados para a consecução dos cursos. Assim, a estrutura pedagógica atuante em cursos $\mathrm{EaD}$ é constituída pelos seguintes profissionais (MILL, 2010): professor-conteudista, professor-coordenador de disciplina, professor-formador (ou professor-aplicador), tutor (presencial e virtual), equipe multidisciplinar, com especialistas em mídia impressa, audiovisual, virtual, vídeo e webconferência, além de outros profissionais eventuais, projetista educacional e uma equipe coordenadora.

Caracteriza-se, nessa concepção, a complexidade que envolve a docência no ensino a distância, a qual requer a atuação de diversos atores e a composição de novos papéis, como o trabalho do professor-tutor, também definido por Mill (2010).

Considerando-se o foco do presente estudo, dar-se-á destaque à figura do professor-tutor, do qual se demanda além do conhecimento do conteúdo da área de formação do curso, o desenvolvimento de competências favoráveis ao trabalho em equipe, a orientação e estímulos dos discentes aos estudos no ambiente virtual de aprendizagem; a atuação como docente e articulador de todo o processo pedagógico. $\mathrm{O}$ objetivo de sua atuação vai ao encontro da promoção da autonomia e interação dos acadêmicos a fim de que, apesar de remotamente, seja possível a consolidação de um espaço de cooperação para a aprendizagem, instigando-os ao desenvolvimento cognitivo individual e em equipe (OLIVEIRA; CERDAS; MAURO, 2013).

\section{PROCEDIMENTOS METODOLÓGICOS}

O delineamento da investigação quanto ao objetivo é compreendido como uma pesquisa descritiva e aplicada, uma vez que "[...] caracteriza-se por seu interesse prático, isto é, que os resultados sejam aplicados ou utilizados [...] na solução de problemas que ocorrem na realidade" (MARCONI; LAKATOS, 2007, p. 20).

Quanto aos meios da pesquisa, fez-se uso dos métodos de pesquisa bibliográfica e de estudo de caso. A pesquisa bibliográfica foi possível se realizar a construção teórica e fornecer o embasamento para o estudo proposto a partir de publicações em periódicos, livros, revistas e artigos científicos.

O estudo de caso, segundo Triviños (2006), tem como finalidade aprofundar a descrição de determinada realidade, não possuindo caráter de generalização, tornando seus resultados válidos para aquele caso específico. Este estudo aprofundou-se na realidade da tutoria do curso de graduação na modalidade a distância do Departamento de Ciências da Administração da UFSC, no que diz respeito aos aspectos relacionados à aprendizagem informal dentro do Programa Universidade Aberta do Brasil, o qual está em sua quarta edição.

Utilizou-se do censo para a aplicação de um questionário aos tutores envolvidos no projeto, visto que foi aplicado a todos os integrantes da equipe. A população alvo é composta pelos tutores a distância do curso de graduação na modalidade a distância do Departamento de Ciências da Administração da UFSC, os quais compõem os sujeitos da pesquisa.

Para efetuar a coleta dos dados, utilizou-se de dois tipos de instrumentos: o questionário e a observação participante. Quanto à aplicação do questionário, foram enviados via e-mail aos sujeitos da pesquisa.

Durante o estudo, foi feita a observação da equipe, ou seja, foram observados todos os procedimentos que são estabelecidos nos processos de trabalho, as demandas de serviços, a forma de atuação dos tutores, a fim de estabelecer parâmetros para o 
tratamento dos dados qualitativos. O presente trabalho, dada à natureza de seu objeto, envolveu coleta de dados quantitativos e de dados qualitativos.

A análise é uma tentativa de evidenciar as relações existentes entre o fenômeno estudado e outros fatores. Essas relações podem ser "estabelecidas em função de suas propriedades relacionais de causa-efeito, produtor-produto, de correlações, de análise de conteúdo etc" (TRUJILLO, 1974, p. 178).

\section{ANÁLISE E DISCUSSÃO DOS RESULTADOS}

Na Universidade Federal de Santa Catarina - UFSC, especificamente no Departamento de Ciências da Administração, o programa Universidade Aberta do Brasil está em sua quarta edição obtendo a aprovação do currículo em 2014.2. O curso tem a duração de quatro anos e meio, o qual passa a integrar a Portaria $n^{\circ}$ 138/CGRAD/2013, de 13 de novembro de 2013, que trata da aprovação do curso pela Resolução $\mathrm{n}^{\circ}$ 25/2013/CGRAD, de 14 de novembro de 2013.

Tal curso, criado pelo MEC, visou atender estudantes distribuídos pelos estados do Paraná, Rio Grande do Sul e Santa Catarina. Conta atualmente com 295 alunos distribuídos em seis Polos, a saber: Céu Azul/PR, São Francisco de Paula/RS, Laguna/SC, Chapecó/SC, Blumenau/SC e Canelinha/SC.

A UAB4 conta com uma equipe de 14 tutores a distância, sendo alocados cerca de dois tutores por Polo, para o desenvolvimento do ensino e aprendizagem, um Coordenador de Curso, uma Coordenadora de Tutoria, uma Supervisora de Tutoria e uma equipe Técnica para lidar com as tecnologias de informação.

Acerca do perfil dos respondentes, constata-se a predominância de tutores do gênero feminino, totalizando $75 \%$ do corpo de tutores. Os tutores do gênero masculino correspondem a $25 \%$ do total dos respondentes. Destaca-se nos resultados da pesquisa que a tutoria conta com uma equipe com alto índice de conhecimento, há uma evidencia desta afirmação ao constatar que a maioria dos tutores possui mestrado concluído ou em andamento, representando $66,67 \%$ do total de respondentes. As informações do perfil revelam-se importantes por caracterizarem a população estudada, bem como identificarem a qualificação existente entre os tutores, aspecto diretamente relacionado com o processo de aprendizagem e com a capacidade de orientação nas diferentes disciplinas. Neste viés, nota-se a predominância do tempo de experiência dos respondentes, 66,67\%, entre 1 e 2 anos, inferindo que os tutores começaram suas atividades com início do projeto UAB4 em 2014.

Ao serem questionados acerca da percepção do próprio tutor sobre a capacitação que recebem para exercer as funções inerentes ao papel que ocupam, revelou-se que 50\% dos respondentes consideram-se plenamente capacitados, $33,33 \%$ se consideram parcialmente capacitados e $11,67 \%$ se consideram insuficientemente capacitados.

Resultado semelhante foi encontrado entre os respondentes quando questionados sobre a percepção quanto à sua inserção em uma equipe polidocente, no qual há espaço para discussões e debates sobre a melhoria do curso. Metade dos tutores considera-se plenamente inserido nesta equipe e a outra metade considera-se parcialmente inserido, porém com pouca liberdade para opinar e participar dos processos de construção do curso.

Os respondentes que identificaram não estarem plenamente capacitados apontam como aspectos dificultadores os seguintes itens: conhecimento restrito sobre os conteúdos em virtude da ampla gama de disciplinas que o curso oferece; má qualidade dos treinamentos ofertados no início do curso, bem como a ausência destes treinamentos aos tutores que ingressaram na equipe após o início do projeto; falta de conhecimento em didática tornando mais difícil a função de orientar os alunos; o não aprofundamento das 
capacitações quanto aos conhecimentos de cada disciplina; insegurança quanto à correção das provas e atividades devido aos múltiplos critérios de cada professor; comunicação entre professores e tutores falha e ineficaz e o fato de que as capacitações não cumprem a função de capacitar.

Observa-se pelos relatos dos respondentes que o processo de aprendizagem formal oferecido pela coordenação do curso não está atendendo às necessidades e demandas de todos os tutores.

$\mathrm{Na}$ percepção dos tutores que se consideram plenamente capacitados, fatores como a formação acadêmica e a experiência anterior como tutor contribuem para sua aprendizagem, além de características individuais como disponibilidade, comprometimento e curiosidade. Os respondentes afirmam considerar as trocas $\mathrm{e}$ interações entre colegas uma rica fonte de aprendizagem, as quais colaboram para sua capacitação. Esse relato converge com a visão de Gherardi (2006) e Antonello e Godoy (2011) sobre aprendizagem como um fenômeno social e interacional.

Acerca do escopo de atuação dos tutores foram questionadas quais atividades o compõem, sendo duas apontadas por todos os tutores: conhecimento em todas as áreas e competência para orientar e estimular os alunos para o estudo a distância. Outras duas características recorrentemente citadas foram: participação no processo avaliativo dos alunos (11 vezes) e competência para trabalhar em equipe (10 vezes).

Não obstante, no que se refere à análise a respeito do escopo de atuação dos tutores, duas atividades foram pouco citadas: atuar no processo pedagógico do curso (4 vezes) e promover espaços coletivos de construção do conhecimento entre os tutores (1 vez). Percebe-se que a questão da troca de conhecimento por meio de espaços compartilhados não foi considerada como uma atividade presente no escopo de atuação dos tutores pela maioria dos respondentes. É por meio destes espaços, segundo Flach e Antonello (2011), que ocorrem as trocas e interações entre os atores podendo, inclusive, culminar no surgimento de comunidades de prática (WENGER, 2000).

Todos os respondentes revelaram possuir algum tipo de dificuldade quanto à orientação das disciplinas. Dentre as principais dificuldades elencadas, ressalta-se uma opinião onde o respondente relata que o fato de nem todos os tutores possuírem graduação em administração caracteriza-se como uma limitação, a qual é agravada pela inefic ácia das capacitações dos professores.

A comunicação é apontada por vários autores como atributo fundamental no processo de aprendizagem, seja ela formal ou informal. Questionou-se a respeito de qual meio de comunicação o tutor considera ser o mais efetivo dentre os listados. O e-mail institucional constituiu forma unânime de comunicação entre os tutores, sendo ainda, um resultado interessante, o alto índice de respostas apontando o aplicativo de trocas de mensagens pelo celular (whatsapp) e mensagens de texto, um mecanismo de comunicação informal.

O e-mail institucional, por sua vez, foi apontado como a forma mais segura e confiável de comunicação. As mensagens de texto e via whatsapp são consideradas efetivas por parte dos tutores em virtude de seu caráter célere, acesso diário e agilidade na resolução de problemas imediatos. Os encontros presenciais, foram apontados como importantes formas de troca de informações, compartilhamento de experiências e dúvidas, exposição de problemas, bem como propícios ao contato mais próximo entre os tutores, reforçando o sentimento de equipe.

Percebe-se a existência de interação, trocas de experiências e vivências, as quais ocorrem informalmente antecedendo as capacitações formais. Essa situação converge com a análise feita por Flach e Antonello (2010) que afirmam que a aprendizagem informal pode ocorrer em situações formalmente estruturadas. 
Durante a consecução da pesquisa, o ambiente virtual de aprendizagem (Moodle) foi identificado como importante ferramenta tecnológica em que ocorre a maioria das atividades do curso e no qual os tutores realizam várias de suas atividades. Em virtude disso, os tutores foram questionados quanto às contribuições desta ferramenta para a sua aprendizagem enquanto profissionais. Alguns respondentes não entendem o Moodle como ferramenta de aprendizagem de suas atividades. Eles enxergam que essa ferramenta somente proporciona a aprendizagem dos alunos. Cita-se alguns dos relatos obtidos no questionário "Que tipo de aprendizagem?" e "O Moodle se constitui principalmente como uma ferramenta de aprendizagem para os alunos".

Foi levantada uma importante questão acerca do compartilhamento de informações pelo Moodle, o qual favorece muito a aprendizagem informal. Cita-se o relato: "Consigo ver a resposta dos outros tutores nos fóruns e a correção das atividades e avaliações [feitas por eles], muitas vezes me inspiro nelas e também aprendo com elas. Ter esse acesso é importante".

Quanto à identificação com o trabalho a distância, todos os respondentes revelaram gostar de trabalhar desta forma devido à autonomia proporcionada por esta modalidade de trabalho e por poder realizar as atividades por meio virtual. Foi apontado por $25 \%$ dos respondentes que em alguns momentos sua aprendizagem é prejudicada por não estar em contato diário com seus colegas e supervisores. "Entendo que o contato face a face é importante para o aprendizado, uma vez que fica mais fácil de explicar o problema e ter a percepção emocional da situação. "

No que tange às formas de aprendizagem, solicitou-se aos respondentes que atribuíssem notas de 1 a 6 àquelas percebidas no contexto da tutoria.

Fica evidenciado que as formas de aprendizagem informais são recorrentemente avaliadas como de maior efetividade entre os tutores em relação às formais. As práticas diárias e experiências cotidianas e a troca de informações e interações com colegas tutores por meio virtual atingiram as maiores pontuações de acordo com a escala utilizada no questionário. Em contrapartida, as capacitações formais com supervisores, instrutores e professores obtiveram as menores pontuações, revelando que os tutores consideram que a aprendizagem formal, da maneira como vem ocorrendo atualmente, pouco vem contribuindo para o seu processo de aprendizagem.

Percebe-se que a leitura de manuais e textos por si mesmo foi uma forma de aprendizagem significativamente bem avaliada, reforçando a ideia de que a aprendiza gem é um processo individual e cognitivo, contrapondo-se à perspectiva sociológica da aprendizagem, na qual o contexto social e as interações interpessoais constroem o conhecimento de forma compartilhada (GHERARDI, 2006).

Outros meios de aprendizagem citados pelos respondentes são: entrar em contato com tutores mais experientes e de outras edições do programa, trocar informações com os alunos, pesquisa na internet, contato com professores além das capacitações e com pessoas com maior domínio sobre os conteúdos das disciplinas.

Quando questionados sobre a primeira atitude a ser tomada frente a uma dificuldade, constatou-se que há a predominância de envio de e-mails institucionais para o grupo de tutores, representando pouco mais de $58 \%$ das respostas. Da mesma forma, o envio de e-mails para o professor ou tutor líder das disciplinas foi apontado como primeira atitude por $25 \%$ dos respondentes. Os cerca de $17 \%$ restantes relataram que enviaria mensagem utilizando meios de comunicação informal e e-mail à supervisão do curso como primeira alternativa na existência de um problema.

Com o objetivo de conhecer o processo de aprendizagem na tutoria, foi elaborada uma questão aberta na qual o respondente deveria compartilhar uma dificuldade e como encontrou auxilio para solucioná-la. A desorganização das disciplinas quanto à 
transmissão dos objetivos e critérios de avaliação requeridos pelos docentes foi indicada como uma dificuldade recorrente entre o grupo, refletindo na qualidade do trabalho realizado pelos tutores e, consecutivamente, do próprio curso. Um método utilizado para minimizar estes problemas é o envio pelo tutor-líder das orientações gerais de cada disciplina para o grupo, baseando-se no que foi repassado pelos professores quando do momento da capacitação.

As disciplinas oriundas das ciências exatas foram elencadas como de maior dúvida entre os tutores, tanto pela complexidade inerente aos seus conteúdos, quanto pela dificuldade em orientar virtualmente os acadêmicos neste âmbito. A superação destes obstáculos se deu por meio da colaboração entre o grupo de modo a propiciar a compreensão do conteúdo, bem como a melhor maneira de transmiti-lo aos alunos.

Dúvidas relativas à operacionalização do Moodle foram mencionadas por alguns respondentes, indicando que há necessidade de maior treinamento e conhecimento das ferramentas ofertadas pelo ambiente virtual, tornando-o um instrumento de aprendiza gem não apenas ao aluno, mas também ao tutor, englobando seu trabalho pedagógico e administrativo.

De modo geral, é possível perceber que não está totalmente claro para os tutores qual é o seu papel enquanto atores sociais. De acordo com as respostas, muitos se enxergam como meros agentes operacionais, alguns se percebem como agentes ativos no processo de formação acadêmica dos alunos. Fica evidente que é necessário um melhor esclarecimento da função do tutor a partir da disseminação de seu papel. Em conformidade com a Mill (2006), a função do tutor no contexto pesquisado está associada com a figura do professor-tutor. Este fato apenas reforça a necessidade de proporcionar meios de aprendizagem, trocas e compartilhamento de informações e conhecimentos, visando uma melhor capacitação dos profissionais que atuam na tutoria (COELHO JUNIOR; MOURÃO, 2011).

\section{CONSIDERAÇÕES FINAIS}

O presente estudo teve como objetivo o de analisar como é percebida a aprendizagem informal a partir da perspectiva de um grupo de tutores a distância do projeto Universidade Aberta do Brasil na UFSC. A intenção desta pesquisa foi associar a teoria estudada com a realidade empírica onde se dá a aprendizagem dos tutores no contexto investigado. O trabalho traz uma contribuição acadêmica na medida em que explora um campo de conhecimento que carece de pesquisas empíricas sobre o assunto.

Os tutores estão inseridos em um ambiente de múltiplos saberes, tanto por suas formações acadêmicas quanto pela estrutura do curso ao ofertar variadas disciplinas sob orientação desses profissionais. Tais fatores implicam na necessidade constante de reciclagem do conhecimento adquirido, ao passo que gera níveis distintos de dificuldade entre os tutores frente ao tipo de disciplina ministrada.

Em decorrência desse cenário multifacetado, nada insólito o desenvolvimento de meios de aprendizagem além daquela oferecida pela organização, constituindo uma rede de interação entre os tutores que propicia o compartilhamento de informações e troca de experiências que culminam na aprendizagem do grupo.

Nesse sentido, os resultados apontam que os meios de aprendizagem informal são mais efetivos entre os tutores em detrimento da aprendizagem formal, ainda que exista preferência pela utilização de meios de comunicação formal, destacando-se o e-mail institucional, o qual constitui uma base de informações essenciais para a consecução das atividades destes profissionais. 
Todavia, muito embora os resultados indiquem a existência de iniciativas voltadas à aprendizagem informal em uma perspectiva sociológica, retratando um aspecto positivo, notórias são as falhas indigitadas pelos respondentes no que se refere aos mecanismos formais de aprendizagem, sobretudo em relação à utilização do Moodle, à comunicação e às capacitações com os professores das disciplinas. Em uma análise mais ampla, pode-se dizer que as capacitações não oferecem bases didáticas e pedagógicas suficientes para que os tutores desempenhem seu papel de orientação e estímulo ao estudante, culminando na incerteza quanto à real função das capacitações realizadas pelos professores.

Quanto ao Moodle, em decorrência do fato de ser considerado pelos respondentes um ambiente de aprendizagem formal praticamente exclusivo aos alunos, nota-se que a ferramenta perde sua potencialidade como ambiente virtual de aprendizagem na ótica dos tutores. Apesar de garantir o acesso a todas as disciplinas e seus materiais, bem como o acompanhamento das atividades realizadas pelos tutores, percebe-se que os mesmos não o entendem como um repositório de conhecimento, limitando o Moodle a um sistema para disponibilizar informações acadêmicas aos discentes.

Disto extrai-se a necessidade de investimento na capacitação voltada ao desenvolvimento de didática para os tutores e não somente no alinhamento de acordo com as nuances de cada disciplina do curso. Não obstante, ao capacitá-los sob a ótica pedagógica, a autonomia e a visão sistêmica acerca da profundidade das atividades que desempenham são acentuadas, tornando-os mais atuantes e iniciando um processo de auto reconhecimento de suas funções no contexto da Universidade Aberta do Brasil. A partir da internalização de suas reais contribuições para a formação acadêmica dos discentes e de seu papel como professor-tutor, o diagnóstico quanto ao pertencimento e inserção em uma equipe polidocente tende a ser alterado de um viés operacional para uma perspectiva de coparticipação pelo gerenciamento da qualidade do curso, refletindo em um impacto bastante positivo para o projeto.

\section{REFERÊNCIAS}

ANTONELlO, C. S.; GODOY, A. S. Aprendizage m Organizacional no Brasil. Porto Alegre: Bookman, 2011.

BASTOS, A. V. B.; GONDIM, S. M. G.; LOIOLA, E. Aprendizagem organizacional $\mathbf{x}$ organizações que aprendem: características e desafios que cercam essas duas abordagens. Revista de Administração: São Paulo, V. 39, n.3, p. 220-230, 2004.

BISPO, M. S.; MELLO, A. S. A miopia da aprendizagem coletiva nas organizações: existe uma lente para ela? Revista Gestão e Planejamento, Salvador, v.12, n. 3, p. 728$745,2012$.

BLACKER, F. Knowledge and theory of organizations: organizations as activity systems and the reframing of management. Journal of Management Studies, v. 30, n. 6, 1993.

COELHO JUNIOR, F. A.; MOURÃO, L. Suporte à aprendizagem informal no trabalho: uma proposta de articulação conceitual. Revista de Administração Mackenzie: São Paulo, 2011. 
CONLON, T. A review of informal learning literature, theory and implications for practice in the developing global professional competence. Journal of European Industrial Training, v. 28, 2004, p. 283-295.

EASTERBY-SMITH, M.; ARAÚJO, L. Aprendizagem organizacional: oportunidades e debates atuais. In: EASTERBY-SMITH, M.; BURGOYNE, J.; ARAÚJO, L.

Aprendizagem organizacional e organização de aprendizagem: desenvolvimento na teoria e na prática. São Paulo: Atlas, 2001.

FLACH, L.; ANTONELLO, C. S. A teoria sobre aprendizagem informal e suas implicações nas organizações. Revista de Gestão Organizacional, 2010.

GHERARDI, S. Organizational knowledge: the texture of workplace learning. Oxford: Blackwell Publishing, 2006.

MARCONI, M. A.; LAKATOS, E. M. Fundamentos de metodologia científica. 7. ed. São Paulo: Atlas, 2007.

MARSICK, V.; WATKINS, L. Informal and incidental learning in the workplace. Routledge and Kegan Paul, New York, 1990.

MILL, D. et al. O desafio de uma interação de qualidade na Educação a Distância: o tutor e sua importância nesse processo. Cademos da Pedagogia. Ano 02, Volume 02, Número 04. São Carlos: UFSCar. Agosto/dezembro 2008. Disponível em http://www.cadernosdapedagogia.ufscar.br/index.php/cp/article/viewFile/106/63 Acesso em: 02 de nov. 2015.

NICOLINI, D.; GHERARDI; S.; YANOW, D. Knowing in Organizations: A Practice-Based Approach. New York: Sharpe, 2003.

OLIVEIRA, E.A.; CERDAS, L.; MAURO, R.A experiência de EaD no Centro Universitário de Araraquara/SP: o trabalho do professor-tutor na interação dos processos de ensino e aprendizagem. V Seminário Internacional de Educação a distância: meios, atores e processos. Minas Gerais, 2013. Disponível em <https://www.ufmg.br/ead/seminario/anais/pdf/Anais_V_SIEAD.pdf> Acesso em 02 nov. de 2015.

PROJETO PEDAGÓGICO do Curso de Graduação em Administração na Modalidade a Distância Ingresso - 2014 - Cad. Florianópolis, 2014.

RICHARDSON, et al. Pesquisa social: métodos e técnicas. 3. ed. rev. ampl. São Paulo: Atlas, 2007.

STEVENSSON, L.; ELLSTRÖM, P. E.; ABERG, C. Integrating formal and informal learning at the work. Journal of Workplace Learning. V. 16, p. 479-491, 2004.

TRIVIÑOS, A. N. S. Introdução à pesquisa em ciências sociais . São Paulo: Atlas, 2006.

TRUJILlO, A. F. Metodologia da Ciência. 3. Ed. Rio de Janeiro: Kennedy, 1974. 